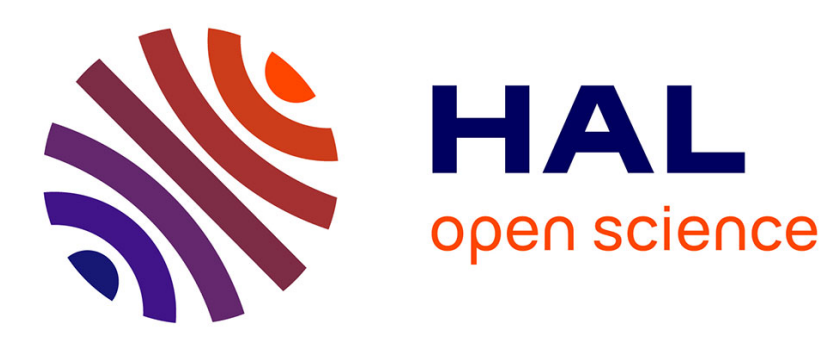

\title{
Effect of temperature on the aggregation behaviour of nonionic surfactants in aqueous solutions \\ R. Zana, C. Weill
}

\section{To cite this version:}

R. Zana, C. Weill. Effect of temperature on the aggregation behaviour of nonionic surfactants in aqueous solutions. Journal de Physique Lettres, 1985, 46 (20), pp.953-960. 10.1051/jphyslet:019850046020095300 . jpa-00232923

\section{HAL Id: jpa-00232923 https://hal.science/jpa-00232923}

Submitted on 1 Jan 1985

HAL is a multi-disciplinary open access archive for the deposit and dissemination of scientific research documents, whether they are published or not. The documents may come from teaching and research institutions in France or abroad, or from public or private research centers.
L'archive ouverte pluridisciplinaire HAL, est destinée au dépôt et à la diffusion de documents scientifiques de niveau recherche, publiés ou non, émanant des établissements d'enseignement et de recherche français ou étrangers, des laboratoires publics ou privés. 
Classification

Physics Abstracts

$33.50 \mathrm{~F}-82.70-64.70 \mathrm{~J}-82.20$

\title{
Effect of temperature on the aggregation behaviour of nonionic surfactants in aqueous solutions
}

\author{
R. Zana and C. Weill \\ Institut Charles Sadron (CRM-EAHP), CNRS-ULP, Greco Microemulsion Strasbourg, \\ 6, rue Boussingault, 67083 Strasbourg Cedex, France
}

(Reçu le 17 juillet 1985, accepté le 2 septembre 1985)

\begin{abstract}
Résumé. - L'effet de la température sur les propriétés micellaires de tensioactifs non ioniques a été étudié par déclin de fluorescence (formation d'excimère intramicellaire) du pyrène solubilisé dans les micelles. Pour les surfactants du type $\mathrm{C}_{12} \mathrm{H}_{25} \mathrm{E}_{n}(\mathrm{E}=$ groupe oxyde d'éthylène; $n=6,8,9)$ le nombre micellaire moyen en nombre $N$ est pratiquement indépendant de la température $T$ quand $T<T_{\mathrm{C}}-35\left(T_{\mathrm{C}}=\right.$ température critique du système) . Dans le domaine $T_{\mathrm{C}}-35<T<T_{\mathrm{C}}$, $N$ augmente avec $T$, jusqu'à $T_{\mathrm{C}}$. Dans le même domaine on note l'existence d'une migration intermicellaire du pyrène. La vitesse de cette migration augmente très rapidement avec $T$. Ce processus semble se produire par l'intermédiaire de collisions entre micelles accompagnées d'une fusion temporaire et partielle des micelles. Un autre surfactant non ionique étudié, le Triton X-100, se comporte de façon un peu différente : $N$ augmente avec $T$ et le processus de migration existe dans tout le domaine de température étudié.
\end{abstract}

\begin{abstract}
The effect of temperature on the aggregation behaviour of nonionic surfactants in aqueous solution has been investigated by means of transient fluorescence probing (intramicellar excimer formation by pyrene). For surfactants of the $\mathrm{C}_{12} \mathrm{H}_{25} \mathrm{E}_{n}$ type ( $\mathrm{E}=$ ethyleneoxide group, $n=6,8,9)$ the number average aggregation number $N$ of the micelle is nearly independent of the temperature $T$ when $T$ is below $T_{\mathrm{C}}-35\left(T_{\mathrm{C}}=\right.$ critical temperature). In the range $T_{\mathrm{C}}-35<T<T_{\mathrm{C}}$, $N$ increases with $T$, up to $T_{\mathrm{C}}$. In the same range, extensive pyrene migration from micelle to micelle is observed. This process is thought to take place through micelle collisions with temporary and partial merging. Triton X-100 was also investigated and found to behave somewhat differently with an increase of $N$ with $T$ and probe migration in the whole $T$-range.
\end{abstract}

\section{Introduction.}

The effect of temperature on the aggregation behaviour of nonionic surfactants of the alkylpolyoxyethyleneglycol monoether type $\mathrm{C}_{m} \mathrm{E}_{n}$ ( $m=$ number of carbon atoms of the alkyl chain, $n=$ number of oxyethylene groups) has been a matter of controversy in the recent literature [1-18]. Recall that the aqueous solutions of $\mathrm{C}_{m} \mathrm{E}_{n}$ are characterized by the so-called cloud temperature $T_{\mathrm{c}}$ above which the solution phase separates [19]. The $T_{\mathrm{c}} v s$. surfactant concentration $C$ curve goes at a certain concentration $C_{\mathrm{C}}$ through a minimum which is the critical temperature $T_{\mathrm{C}}$ of the system [19]. Some authors reported a very large increase of the micelle aggregation number 
$N$ on increasing the temperature to $T_{\mathrm{C}}[1,2,5,12,17]$. Other workers reported a near constancy of the micelle size upon increasing $T[3,4,6,11,13]$. In addition the results appeared to be strongly dependent on the nature of the nonionic surfactant [1-18].

Examination of the reported studies shows that the discrepancies mostly arise because of difficulties in separating the contributions of the changes of micelle size and shape, changes of micelle interactions, and approach of the critical point, in the measured properties.

In order to help understanding the aggregation behaviour of nonionic surfactants in aqueous solutions we have investigated these systems by the fluorescence decay method, using the excimerforming probe pyrene. Recall that this method permits the determination of the micellar number average aggregation number in the actual experimental conditions, that is at a given surfactant concentration, without the need of any extrapolation, as this method is completely insensitive to intermicellar interactions [20-22]. Also it can provide information on the dynamics of processes by which the probe migrates from micelle to micelle $[20,23,24]$. In the case of the nearly waterinsoluble pyrene, intermicellar migration can occur only through collisions between micelles, accompanied by a temporary merging of the collided micelles. Such a process has been evidenced by luminescence decay techniques in the case of droplets in water-in-oil microemulsions [23]. There, collisions can occur as the droplets are electrically neutral. The same may be true in the case of nonionic surfactant micelles as is suggested by a recent EPR investigation [13].

\section{Materials and methods.}

The investigated nonionic surfactants were the $\mathrm{C}_{12} \mathrm{E}_{6}, \mathrm{C}_{12} \mathrm{E}_{8}$ and $\mathrm{C}_{12} \mathrm{E}_{9}$ (synthetized and purified by Dr. Platone from Assoreni, Italy). Their purity was ascertained from the value of their $T_{\mathrm{C}}$ [25] : $52^{\circ}, 78^{\circ}$ and $88^{\circ} \mathrm{C}$, respectively. The sample of Triton X-100, from Rohm and Haas (USA), was used as received.

The fluorescence decay curves were obtained using the same single photon counting apparatus as in previous investigations [26].

For each solution at each temperature, the fluorescence lifetime $\tau_{0}$ of the micelle-solubilized pyrene was measured at very low $(\sim 0.01)$ molar concentration ratio $R=$ [pyrene]/[micelle] where the decay curve is exponential, and at a ratio $R \sim 1$ where the decay curve is biphasic. The $R \sim 1$ curves were fitted to the equation $[23,24]$

$$
I(t)=I(0) \exp \left\{-A_{2} t-A_{3}\left[1-\exp \left(-A_{4} t\right)\right]\right\}
$$

using a non-linear weighted least square procedure, including a convolution of the fitting curve by the lamp profile. $I(t)$ and $I(0)$ are the fluorescence intensities at time $t$, and time $t=0$, and $A_{2}, A_{3}$ and $A_{4}$ are time-independent. The decay data were generally collected over a time range of $800 \mathrm{~ns}$. For the $\mathrm{C}_{12} \mathrm{E}_{6}$ solution, however, the decay data were collected over ranges of 800 and $1500 \mathrm{~ns}$. Both sets of data yielded the same fitting parameters, within the experimental error $( \pm 2-3 \%$ on $\tau_{0}$ and $A_{2}, \pm 10 \%$ on $A_{3}$ and $\pm 10 \%$ on $A_{4}$ ).

The systems for which $A_{2}$ was found to be equal to $\tau_{0}^{-1}$, within the experimental error, are those where no probe migration occurs on the fluorescence timescale (that is, a time duration of about $20 \tau_{0}$, on the basis of the experimental accuracy). Then $A_{2}, A_{3}$ and $A_{4}$ are given by :

$$
A_{2}=\tau_{0}^{-1} ; A_{3}=R \text { and } A_{4}=k_{\mathrm{E}}
$$

where $k_{\mathrm{E}}$ is the rate constant for intramicellar pyrene excimer formation.

The observation $A_{2}>\tau_{0}^{-1}$ indicates that probe migration takes place in the system under study. 
If migration is assumed to occur through collisions, then [23]

$$
\begin{aligned}
& A_{2}=\tau_{0}^{-1}+k_{\text {ex }}\left[\text { pyrene] } k_{\mathrm{E}} / A_{4}\right. \\
& A_{3}=R\left(k_{\mathrm{E}} / A_{4}\right)^{2} \\
& A_{4}=k_{\mathrm{E}}+k_{\mathrm{ex}}[\mathrm{M}]
\end{aligned}
$$

where $k_{\mathrm{ex}}$ is the second order rate constant associated with collisions with migration and $[\mathrm{M}]=$ [micelle] is the micelle concentrations in mole of micelle per litre. The fitting of the decay data to the equations (1) and (3) to (5) permits the determination of $k_{\mathrm{ex}}, k_{\mathrm{E}}$ and $R$. Both in the absence and presence of probe migration, the micelle number average aggregation number $N$ is obtained from $R$ according to :

$$
N=R[\mathrm{C}-\mathrm{CMC}] /[\text { pyrene }] .
$$

Note that, if the mechanism of probe migration is unknown, $k_{\mathrm{E}}$ and $k_{\mathrm{m}}=A_{4}-k_{\mathrm{E}}$ can nevertheless be obtained from the fitting parameters $\tau_{0}, A_{2}, A_{3}$ and $A_{4}$. Whichever the migration mechanism, $k_{\mathrm{m}}$ is the pseudo first order rate constant for probe migration. The study of the change of $k_{\mathrm{m}}$ with [M] gives some indication on the nature of the process of probe migration.

\section{Results and discussion.}

For the $\mathrm{C}_{12} \mathrm{E}_{n}$ surfactants the condition $A_{2}=\tau_{0}^{-1}$ was found to be fulfilled at temperatures more than $30-35^{\circ} \mathrm{C}$ below $T_{\mathrm{C}}$ indicating no probe migration in this $T$-range. On the contrary, at $T>T_{\mathrm{C}}-35, A_{2}$ was found to be larger than $\tau_{0}^{-1}$ and increased rapidly with $T$ as $T_{\mathrm{C}}$ was approached, indicating extensive probe migration. This process was found to occur in Triton $\mathrm{X}-100$ solutions in the whole $T$-range between 0 and $55^{\circ} \mathrm{C}$.

The values of $N$ and $k_{\mathrm{ex}}$ calculated on the basis of equations (1) to (6) are plotted against $T$ in figures 1 and 2 for the investigated surfactants.

Consider first the $\mathrm{C}_{12} \mathrm{E}_{n}$ surfactants. The figures 1 and 2 clearly show that at $T$ below, say, $T_{\mathrm{C}}-35, N$ is nearly independent of $T$ and probe migration is too slow to be detected in the

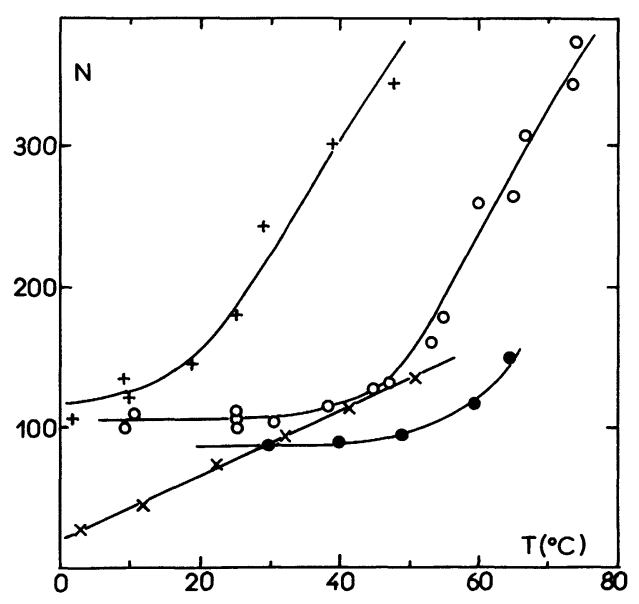

Fig. 1. - Effect of temperature on the micelle aggregation number of $C_{12} E_{6}(+) ; C_{12} E_{8}(0) ; C_{12} E_{9}(\bullet)$ and Triton X-100 $(\times)$. The $N$-values have been calculated assuming pyrene migration through micellar collisions. Surfactant concentrations : $1.3 \%, 3.06 \%, 3 \%$ and $6.3 \%$, respectively. 


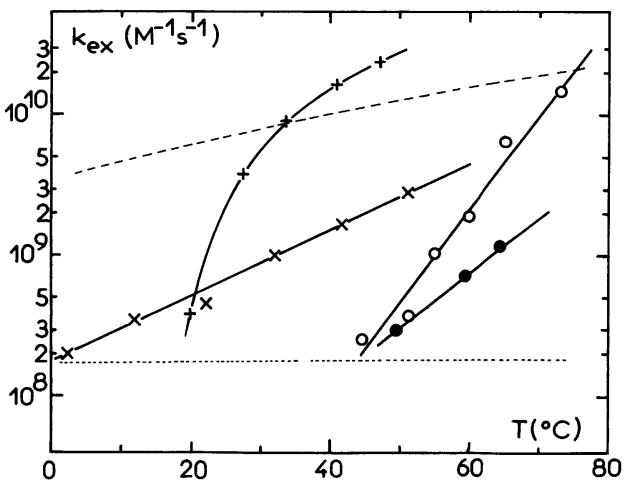

Fig. 2. - Effect of temperature on the rate constant for pyrene intermicellar migration through collisions (same symbols and concentrations as in Fig. 1). The curve in broken line (- - -) shows the diffusion control rate of collision in the absence of intermicellar interactions. The curve in dotted line (...) shows the limit of detection.

present experimental conditions $\left(k_{\mathrm{m}}=A_{4}-k_{\mathrm{ex}}<10^{5} \mathrm{~s}^{-1}\right)$. The constancy of $N$ in the low $T$-range has been observed by other workers with different techniques $[1,11,14]$ and the values of $N$ reported in these studies and in the present one agree, within the experimental error. Also, for $\mathrm{C}_{12} \mathrm{E}_{8}$ in the low $T$-range an increase of concentration from 1 to $20 \%(w / v)$ has produced a $C$-independent aggregation number $N=100 \pm 10$ both in the present study and in a previous investigation [14]. Finally we have found that the presence of $0.8 \mathrm{M} \mathrm{NaCl}$ or $0.3 \mathrm{M} \mathrm{CaCl}_{2}$ had no appreciable effect on the value of $N$ in a $4 \% \mathrm{C}_{12} \mathrm{E}_{8}$ solution up to $T \sim 65^{\circ} \mathrm{C}$.

At temperatures within $35^{\circ} \mathrm{C}$ of $T_{\mathrm{C}}, N$ shows a large increase with $T$. We have noted that in a plot of $N$ vs. $T_{\mathrm{C}}-T$ the data for the $\mathrm{C}_{12} \mathrm{E}_{n}$ surfactants tend to fall on the same curve at $T$ sufficiently close to $T_{\mathrm{C}}$. At the temperature where the change of $N$ with $T$ becomes significant, the probe migration becomes fast enough to be detected on our fluorescence timescale, that is, the difference $A_{2}-\tau_{0}^{-1}$ becomes larger than the experimental error of $c a .5 \%$ on this quantity and increases very rapidly with $T$. It is noteworthy that some of the $k_{\text {ex }}$ values (particularly for $\mathrm{C}_{12} \mathrm{E}_{6}$ ) obtained when using equations (3) to (5) are larger than the values of the diffusion controlled rate of collision between identical micelles, calculated using the Smoluchowski equation (see curve in broken line in Fig. 2). The latter, however, were calculated on the assumption of non interacting micelles. In the present systems, as phase separation takes place at $T_{\mathrm{C}}$, it is likely that the intermicellar interactions are strongly attractive close to $T_{\mathrm{C}}$. This fact was demonstrated to occur at $T$ within $30-35^{\circ} \mathrm{C}$ to $T_{\mathrm{C}}$ by light scattering [11]. Taking such interactions into account cannot be done as the form of the interaction potential is not known. Nevertheless, it remains that the value of the rate of collision calculated at a given $T$ for non interacting micelles represents a lower bound. The values of $k_{\text {ex }}$ found in the present study are very large, much larger than the ones reported for droplet collisions in water-in-oil microemulsions [23], indicating that most intermicellar collisions are accompanied by temporary merging and probe migration, close to $T_{\mathrm{C}}$. Such collisions may be responsible for the observed increase of $N$ with $T$. Indeed at $T>T_{\mathrm{C}}$ - 35 some micelles are in the collided (merged) state and the fluorescence method used will measure a number average value of $N$ which will tend to increase with $T$, in the same manner as the rate of collision.

Two additional series of experiments have been performed in order to gain more information on the process responsible for the pyrene migration. In the first one increasing amounts of the anionic surfactant sodium dodecylsulfate (SDS) were added to a $1.3 \%$ solution of $\mathrm{C}_{12} \mathrm{E}_{6}$. The 
Table I. - Effect of SDS additions on the values of $N$ and $k_{\mathrm{ex}}$ for a $1.3 \%$ solution of $\mathrm{C}_{12} \mathrm{E}_{6}$ at $30.3^{\circ} \mathrm{C}$.

\begin{tabular}{c|c|c}
$\begin{array}{c}\text { Mole fraction } \\
\text { SDS }\end{array}$ & $N\left(^{\mathrm{a}}\right)$ & $k_{\text {ex }}\left(\mathrm{M}^{-1} \mathrm{~s}^{-1}\right)(\mathrm{b})$ \\
\hline 0 & 240 & $6 \times 10^{9}$ \\
6 & 176 & $1.2 \times 10^{9}$ \\
8 & 157 & $3 \times 10^{8}$ \\
10 & 141 & no migration
\end{tabular}

(a) $\pm 10 \% ;\left(^{b}\right) \pm 25 \%$, with a lower limit of detection of $2 \times 10^{8} \mathrm{M}^{-1} \mathrm{~s}^{-1}$.

resulting changes of the values of $N$ and $k_{\text {ex }}$ are listed in table I. It is seen that 8 mole $\%$ SDS with respect to $\mathrm{C}_{12} \mathrm{E}_{6}$ are sufficient to nearly completely inhibit the pyrene migration. This behaviour probably results from the fact that intermicellar collisions between mixed $\mathrm{C}_{12} \mathrm{E}_{6}-\mathrm{SDS}$ micelles are prevented owing to electrostatic repulsions. The addition of SDS is also known to increase $T_{\mathrm{C}}$. Thus, at a given $T$, additions of SDS increase $T_{\mathrm{C}}-T$ and result in a decrease of $N$ and $k_{\text {ex }}$. A similar conclusion was reached by others in a study of the self-diffusion of mixed $\mathrm{C}_{12} \mathrm{E}_{n}-\mathrm{SDS}$ micelles [27]. In the second series of experiments the pseudo-first order rate constant for probe migration $k_{\mathrm{m}}=A_{4}-k_{\mathrm{E}}$ was determined as a function of the micelle concentration [M] , for $\mathrm{C}_{12} \mathrm{E}_{8}$ solutions at $66.5^{\circ} \mathrm{C}$. The results are plotted in figure 3 . It is seen that at least at low $[\mathrm{M}], k_{\mathrm{m}}$ increases linearly with $[\mathrm{M}]$ indicating that migration involves a bimolecular process. This is strongly in favour of migration through micellar collisions. At higher [M] the plot presents a pronounced downward curvature indicating a change in the nature of the migration process. This behaviour cannot be explained yet and requires additional experiments.

The activation energy $E_{\mathrm{E}}^{\neq}$for pyrene excimer formation in the various micelles have been determined from the $\log N k_{\mathrm{E}} v s$. $1 / T$ plots [26] and found to be $5.3 \pm 1.5 ; 7.3 \pm 1.5$ and $5.8 \pm$ $1.5 \mathrm{kcal} / \mathrm{mol}$ for $\mathrm{C}_{12} \mathrm{E}_{6}, \mathrm{C}_{12} \mathrm{E}_{8}$ and $\mathrm{C}_{12} \mathrm{E}_{9}$, respectively. These values are close to those found for ionic surfactant micelles [26]. Another result concerns the $T$-dependence of the rate constant for probe migration $k_{\mathrm{ex}}$ and its corresponding activation energy $E_{\mathrm{ex}}^{\neq}$. Values of 20 to $30 \pm 5 \mathrm{kcal} /$ mol have been found for the $\mathrm{C}_{12} \mathrm{E}_{n}$ surfactants.

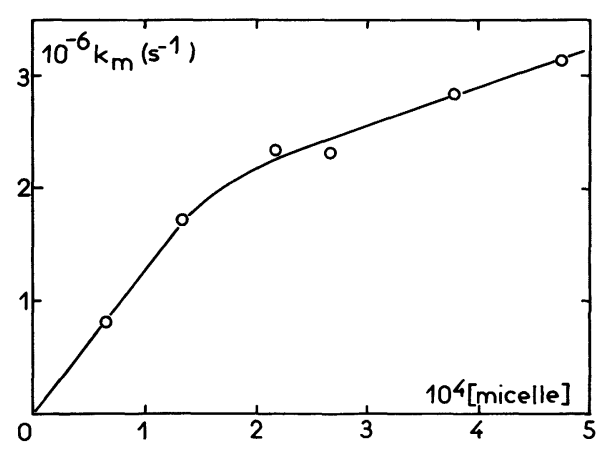

Fig. 3. - Variation of the rate constant for pyrene intermicellar migration with the micellar concentration at $66.5^{\circ} \mathrm{C}$ in $\mathrm{C}_{12} \mathrm{E}_{8}$ micellar solutions (expressed in mole of micelle per litre). 
The results for Triton X-100 clearly depart from those for the $\mathrm{C}_{12} \mathrm{E}_{n}$ surfactants. Thus both $N$ and $k_{\text {ex }}$ increase nearly linearly with $T$ in the whole $T$-range. Also, the values $E_{\mathrm{E}}^{\neq}=9.4 \pm$ $1.5 \mathrm{kcal} / \mathrm{mol}$ is larger than that found for the $\mathrm{C}_{12} \mathrm{E}_{n}$ surfactant. It should be noted that at a given $T$ the value of $N k_{\mathrm{E}}$ is much smaller for Triton $\mathrm{X}-100$ than for the other three surfactants. Thus, at $25{ }^{\circ} \mathrm{C}, N k_{\mathrm{E}}$ equals $1.8 \times 10^{8} \mathrm{~s}^{-1}$ for Triton $\mathrm{X}-100$ and about $(7 \pm 1) \times 10^{8} \mathrm{~s}^{-1}$ for the $\mathrm{C}_{12} \mathrm{E}_{n}$. These results suggest the existence of some interaction between pyrene and Triton X-100 [26]. Finally, the value $E_{\mathrm{ex}}^{\neq}=10 \pm 3 \mathrm{kcal} / \mathrm{mol}$ found for Triton $\mathrm{X}-100$ is much smaller than the corresponding values for the $\bar{C}_{12} E_{n}$ surfactants. This last result suggests that the activated state for intermicellar probe migration, that is the temporary and partially merged micelle dimer, is more easily formed in the case of Triton X-100 than of $\mathrm{C}_{12} \mathrm{E}_{n}$. To a large extent this conclusion is in line with the fact that Triton X-100 micelles are (i) less compact than $\mathrm{C}_{12} \mathrm{E}_{n}$ micelles in view of their partly branched, and partly rigid hydrophobic moiety; and (ii) less stable than $\mathrm{C}_{12} \mathrm{E}_{n}$ micelles in view of their lower aggregation number (see Fig. 1), and higher CMC.

As a last indication, it is pointed out that the activation energy for the pyrene fluorescence decay has been found to be $0.8 \pm 0.2 \mathrm{kcal} / \mathrm{mol}$ for the four non ionic surfactants. This value is close to that found for pyrene in micelle of ionic surfactants and [26] also in homogeneous media, such as cyclohexane [28].

Before closing this paper some comments should be made about the analysis of the data by means of equations (1) to (6). This analysis neglected (i) the possible effect of the pyrene excimer dissociation [26], and (ii) the problems associated with micelle size polydispersity [17, 29]. Concerning point (i) we have shown elsewhere [26] that the excimer dissociation contribution may affect the data at temperature above $40^{\circ} \mathrm{C}$. In the present case excimer dissociation would result in calculated $N$-values somewhat lower than the real ones. The increase of $N$ with $T$ upon approaching $T_{C}$ would be thus somewhat larger than it appears on the plots of figures 1 and 2. The problem of polydispersity is more difficult to deal with. The calculation of Almgren and Löfroth [29] indicate that problems may arise when the residence time of the probe in a given micelle is shorter than the average time required for the size of a given micelle to fluctuate over the whole width of the size distribution curve. Thus Almgren and Löfroth investigated $\mathrm{C}_{12} \mathrm{E}_{6}$ solutions [17] and interpreted their data on the basis of polydispersity, neglecting completely probe migration. This was equivalent to assuming $A_{2}=\tau_{0}^{-1}$ in the whole $T$-range. Their decay curves however stretched only over $750 \mathrm{~ns}$ which is not a sufficient time interval to ascertain whether migration is taking place. This led to aggregation numbers much larger than those obtained in the present investigation. We have analysed our decay data for $C_{12} E_{6}$, which were collected over a time of $1500 \mathrm{~ns}$ after the flash, with a three parameter fitting procedure on the assumption that $A_{2}=\tau_{0}^{-1}$ and obtained for instance at $48^{\circ} \mathrm{C}$ a $N$-value close to that reported by Almgren and Löfroth [17]. However the fit was very bad when compared with the four parameter fit which does not require the assumption $A_{2}=\tau_{0}^{-1}$. A somewhat smaller difference in the quality of the three and four parameter fits was found when the decay curve was analysed over $800 \mathrm{~ns}$ only. These results demonstrate the existence of the migration of the probe through intermicellar collisions, since the residence time of pyrene in micelles is very long with respect to $\tau_{0}[30]$.

Such collisions may take place between full sized micelles in which case the treatment used in this paper is fully valid. They may also take place between full sized micelles and small aggregates, as the system tends to become polydisperse as $N$ becomes larger, close to $T_{\mathrm{C}}$. Such processes have been shown to take place in concentrated solutions of some ionic surfactants, where the micellar aggregation number is large enough [31] and may also occur in the case of nonionic surfactants. They were not accounted for in the present study. Nevertheless, collisions permit very rapid changes of micellar sizes, much faster than the ones discussed by Almgren and Löfroth $[17,29]$ which involved stepwise association-dissociation of one surfactant at a time to/from an aggregate. Then, the problem raised by these authors becomes less important; i.e., the measured 
$N$ are not much affected and they do represent number average aggregation numbers. It remains that owing to the possible existence of collisions between full sized micelles and small aggregates the values of $N$ and $k_{\text {ex }}$ measured in the present study at $T$ close to $T_{\mathrm{C}}$ may only have a semi quantitative signification.

\section{Conclusion.}

The present fluorescence probing study reveals a modest growth of the micelles in solutions of nonionic surfactants as $T$ approaches $T_{\mathrm{C}}$, but no growth at $T<T_{\mathrm{C}}-35$ for the $\mathrm{C}_{12} \mathrm{E}_{n}$ surfactants. It also reveals that micelles can collide and remain in contact a time sufficiently long to allow the passage of a micelle solubilized probe from one to the other collided micelle. The frequency of such collisions becomes measurable at $T \sim T_{\mathrm{C}}-35$ where the intermicellar interactions start becoming attractive and increases very rapidly with $T$ up to $T_{\mathrm{C}}$, where its value is close to that for a diffusion controlled process. Triton X-100 shows a somewhat different behaviour owing to its different hydrophobic moiety.

\section{Acknowledgments.}

The authors are indebted to Drs. Cesari, Platone and Corno for the gift of the purified $\mathrm{C}_{12} \mathrm{E}_{n}$ surfactants and for informations on these compounds, and to the PIRSEM (CNRS) for its financial support (AIP No 2201).

\section{References}

[1] Ottewlll, R., Storer, C. C. and Walker, T., Trans. Faraday Soc. 63 (1967) 2796.

[2] CoRKILl, J. and WalKer, T., J. Colloid Interface Sci. 39 (1972) 621.

[3] Corti, M. and Degiorgio, V., Phys. Rev. Lett. 45 (1980) 1045 ; J. Phys. Chem. 85 (1981) 1442 and references therein.

[4] Corti, M., Degiorgio, V. and Zulauf, M., Phys. Rev. Lett. 48 (1982) 1617.

[5] Cebula, D. and Ottewill, R., Colloid Polymer Sci. 260 (1982) 1118.

[6] Triolo, R., Magid, L., Johnson, J. and Child, R., J. Phys. Chem. 86 (1982) 3689.

[7] Hayter, J. and Zulauf, M., Colloid Polymer Sci. 260 (1982) 1023.

[8] Zulauf, M. and Rosenbuch, J., J. Phys. Chem. 87 (1983) 856.

[9] Nilson, P., Wennerstrom, H. and Lindman, B., J. Phys. Chem. 87 (1983) 1377.

[10] Nilson, P. and Lindman, B., J. Phys. Chem. 87 (1983) 456.

[11] Fujmatsu, H., Takagi, T., Matsuda, H. and Kuroiwa, S., J. Colloid Interface Sci. 94 (1983) 237.

[12] Brown, W., Johnsen, R., Stilbs, P. and Lindman, B., J. Phys. Chem. 87 (1983) 4548.

[13] Di Meglio, J. M., Paz, L., Dvolaitzky, M. and Taupin, C., J. Phys. Chem. 88 (1984) 6036.

[14] Corti, M., Degiorgio, V., Hayter, J. and Zulauf, M., Chem. Phys. Lett. 109 (1984) 579.

[15] Magid, L., Triolo, R. and Johnson, J., J. Phys. Chem. 88 (1984) 5730.

[16] Corti, M., Minero, C. and Degiorgio, V., J. Phys. Chem. 88 (1984) 309.

[17] Almgren, M. and Löfroth, J., in Surfactants in Solutions, K. L. Mittal and B. Lindman, Eds. (Plenum Press, New York) 1984, vol. I, p. 627.

[18] Degiorgio, V., Piazza, R., Corti, M. and Minero, C., J. Chem. Phys. 82 (1985) 1025.

[19] Mitchell, D. J., Tiddy, G., Waring, L., Bostock, T. and McDonald, M., J. Chem. Soc. Faraday Trans. I 79 (1983) 975.

[20] Tachiya, M., Chem. Phys. Lett. 33 (1975) 289.

[21] Atik, S., Nam, M. and Singer, L., Chem. Phys. Lett. 67 (1979) 75.

[22] Infelta, P. and Grätzel, M., J. Chem. Phys. 70 (1979) 179.

[23] Atik, S. and Thomas, J. K., Chem. Phys. Lett. 79 (1981) 351 ; J. Am. Chem. Soc. 103 (1981) 3543.

[24] Dederen, J., Van Der Auweraer, M. and De Schryver, F., Chem. Phys. Lett. 68 (1979) 451 and J. Phys. Chem. 85 (1981) 1198. 
[25] Tabata, Y., Ueno, M. and Meguro, K., J. Am. Oil. Chem. Soc. 61 (1984) 1123.

[26] Malliaris, A., Le Moigne, J., Sturm, J. and Zana, R., J. Phys. Chem. 89 (1985) 2709.

[27] Nilsson, P. and Lindman, B., J. Phys. Chem. 88 (1984) 5391.

[28] Birks, J., Dyson, D. and Munro, I., Proc. R. Soc. London A 275 (1963) 575.

[29] Almgren, M. and Löfroth, J., J. Chem. Phys. 76 (1982) 2734.

[30] Almgren, M., Grieser, F. and Thomas, J. K., J. Am. Chem. Soc. 101 (1979) 279.

[31] Malliaris, A., Lang, J. and Zana, R., submitted for publication. 